\title{
Tumour cell retention of rucaparib, sustained PARP inhibition and efficacy of weekly as well as daily schedules
}

\author{
J Murray ${ }^{1}$, H Thomas ${ }^{1}$, P Berry ${ }^{1}$, S Kyle ${ }^{1}$, M Patterson ${ }^{1}$, C Jones ${ }^{1}$, G Los $^{2}$, Z Hostomsky ${ }^{2}$, E R Plummer ${ }^{1}$, \\ A V Boddy ${ }^{1}$ and N J Curtin ${ }^{*}, 1$ \\ ${ }^{1}$ Northern Institute for Cancer Research, Framlington Place, The Medical School, Newcastle University, Newcastle upon Tyne, \\ UK and ${ }^{2}$ Pfizer Global Research and Development, San Diego, CA, USA
}

\begin{abstract}
Background: Poly(ADP-ribose) polymerase-1 (PARP) inhibitors (PARPi) exploit tumour-specific defects in homologous recombination DNA repair and continuous dosing is most efficacious. Early clinical trial data with rucaparib suggested that it caused sustained PARP inhibition. Here we investigate the mechanism of this durable inhibition and potential exploitation.

Methods: Uptake and retention of rucaparib and persistence of PARP inhibition were determined by radiochemical and immunological assays in human cancer cell lines. The pharmacokinetics and pharmacodynamics of rucaparib were determined in tumour-bearing mice and the efficacy of different schedules of rucaparib was determined in mice bearing homologous recombination DNA repair-defective tumours.
\end{abstract}

Results: Rucaparib accumulation is carrier mediated ( $\mathrm{Km}=8.4 \pm 1.2 \mu \mathrm{M}, \mathrm{Vmax}=469 \pm 22 \mathrm{pmol}$ per $10^{6}$ cells per $\left.10 \mathrm{~min}\right)$, reaching steady-state levels $>10$ times higher than the extracellular concentration within $30 \mathrm{~min}$. Rucaparib is retained in cells and inhibits PARP $\geqslant 50 \%$ for $\geqslant 72 \mathrm{~h}$ days after a 30 -min pulse of $400 \mathrm{~nm}$. In Capan-1 tumour-bearing mice rucaparib accumulated and was retained in the tumours, and PARP was inhibited for 7 days following a single dose of $10 \mathrm{mg} \mathrm{kg}^{-1}$ i.p or $150 \mathrm{mg} \mathrm{kg}^{-1}$ p.o. by $70 \%$ and $90 \%$, respectively. Weekly dosing of $150 \mathrm{mg} \mathrm{kg}^{-1}$ p.o once a week was as effective as $10 \mathrm{mg} \mathrm{kg}^{-1}$ i.p daily for five days every week for 6 weeks in delaying Capan-1 tumour growth.

Conclusions: Rucaparib accumulates and is retained in tumour cells and inhibits PARP for long periods such that weekly schedules have equivalent anticancer activity to daily dosing in a pre-clinical model, suggesting that clinical evaluation of alternative schedules of rucaparib should be considered.

Poly(ADP-ribose) polymerase-1 (PARP)is activated by DNA breaks and has a crucial role in the recruitment of repair proteins to the breaks (El-Khamisy et al, 2003). Poly(ADP-ribose) polymerase- 1 is the most abundant of a family of PARP enzymes, and together with PARP-2 (and to a limited extent PARP-3) is responsible for facilitating DNA repair (De Vos et al, 2012). Poly(ADP-ribose) polymerase-1 inhibitors (PARPi) were first developed to inhibit repair and increase the antitumour activity of DNA-damaging chemotherapy and radiotherapy. Where tested, they inhibit PARP-1 and PARP-2 (Wahlberg et al, 2012). It is well established that PARPi increase the persistence of DNA breaks and the cytotoxicity of ionising radiation, DNA methylating agents and topoisomerase I poisons in cultured cells and the antitumour activity of these agents in xenograft models (Javle and Curtin, 2011). The first clinical trial of a PARPi, AG014699 (now called rucaparib) in cancer patients in 2003 was in combination with temozolomide (Plummer et al, 2008).

However, the discovery that cells and tumour xenografts defective in homologous recombination DNA repair, including BRCA1 and BRCA2 mutations, were selectively killed by PARPi

*Correspondence: Professor NJ Curtin; E-mail: nicola.curtin@ncl.ac.uk

Revised 15 January 2014; accepted 29 January 2014; published online 20 February 2014

(c) 2014 Cancer Research UK. All rights reserved 0007-0920/14 
(Bryant et al, 2005; Farmer et al, 2005) led to a heightened interest in PARPi as single agents. These data provided a new paradigm in cancer treatment that of targeting the DNA repair defect that contributed to the initiation of the cancer by inhibiting a complementary pathway. Several PARPi are now undergoing clinical investigation (Do and Chen, 2013).

Pre-clinical studies with PARPi reveal that higher concentrations and doses and longer exposure periods are required for single-agent activity than for chemo- or radio- combination studies. This is because as a single agent, PARPi rely on inhibiting the repair of endogenously generated DNA single-strand breaks, which stall replication forks and require homologous recombination DNA repair for resolution. Although DNA single-strand break arise endogenously at quite a high rate (Lindahl, 1993), poly(ADPribose) polymerase- 1 is a highly abundant enzyme, and it is likely that unless virtually completely inhibited the single-strand break will largely be repaired before S-phase. Long exposures are required to ensure that all cells pass through S-phase at least once during the exposure period. Rucaparib was more effective against Capan-1 xenografts if given daily for 5 days every week for 6 weeks than once a day for 10 days (Drew et al, 2011). Much lower concentrations and doses are needed in combination with a DNA-damaging agent because, even if not totally inhibited, there is likely to be insufficient PARP activity to facilitate the repair of sudden high levels of DNA damage. As single-agent high doses and long exposures are nontoxic, but in combination with cytotoxic agents only lower doses and shorter exposures are tolerated. Singleagent rucaparib was nontoxic to mice on a repeated 5-day schedule at a dose of $50 \mathrm{mg} \mathrm{kg}^{-1}$ for 6 months, but in combination with temozolomide $1 \mathrm{mg} \mathrm{kg}^{-1}$ daily for five days was the effective but maximum tolerated dose (Thomas et al, 2007; Drew et al, 2011). Data emerging from the clinic also show that tolerable doses of single-agent PARPi frequently result in grade $3 / 4$ myelosuppression in chemotherapy combination studies requiring dose reduction of the companion cytotoxic agent (Do and Chen, 2013).

In pre-clinical studies, AG14361 (structurally similar to rucaparib) distributed well to the tumour and was retained in the tumour after clearance from the plasma (Calabrese et al, 2004). As part of the initial clinical trial, pharmacodynamic measurements of PARP activity in peripheral blood mononuclear cells revealed that PARP activity was inhibited for long periods and indeed was still suppressed 3 days after the final of five daily doses (Plummer et al, 2008). This indicated that rucaparib may be retained in cells and inhibit PARP longer than expected from the PK measurements, and that an intermittent schedule may be as effective as daily dosing. Clinical trials with PARPi as single agents identified neurological side effects, for example, somnolence (Fong et al, 2009); we therefore also investigated the effect of rucaparib in the brain. In the study reported here we show that uptake of rucaparib is carrier mediated, it accumulates and is retained within cancer cells and tumour xenograft but not brain tissues. Also, that a pulse of rucaparib results in PARP inhibition for several days in cell culture and that, after a single dose of rucaparib, PARP is inhibited in tumour xenografts for at least a week. We also show that single weekly administration of rucaparib is as effective as five daily doses per week.

\section{MATERIALS AND METHODS}

Cell lines and reagents. All reagents were of the highest purity and obtained from Sigma (Poole, UK) unless otherwise stated. SW620, human colorectal cancer cells, and Capan-1, BRCA2 mutant human pancreatic cancer cells, were obtained from the ATCC (Manassas, VA, USA) and MX-1, human BRCA1 mutant breast cancer cells, were obtained from Cell Line Services
(Eppelheim, Germany). The cells were maintained in exponential phase in RPMI-1640+10\% FBS, RPMI-1640+15\% FBS and DMEM:Ham's F12 (1:1/vol:vol) + 2 mM L-glutamine + 10\% FBS, respectively, at less than 30 passages from receipt or authentication (LGC Standards, Teddington, UK) in a humidified atmosphere of $5 \% \mathrm{CO}_{2}$ in air at $37^{\circ} \mathrm{C}$. Cells were confirmed mycoplasma free (Mycoalert; Lonza, Rockland, ME, USA).

Rucaparib accumulation studies. Cell number and viability in each assay was determined by haemocytometer counting using Trypan-blue exclusion. Rucaparib uptake was determined using $\left[{ }^{14} \mathrm{C}\right] \mathrm{AG} 014699$ (rucaparib, Pfizer Oncology, La Jolla, CA, USA). $\left[{ }^{3} \mathrm{H}\right]$ Sucrose or inulin, which do not enter cells with intact plasma membranes, were included to allow calculation of the amount of extracellular fluid. From this value the amount of non-transported contaminating $\left[{ }^{14} \mathrm{C}\right]$ rucaparib in the extracellular space was calculated and, subtracted from the total. For time course of uptake experiments exponentially growing SW620 cells were incubated with $400 \mathrm{~nm}\left[{ }^{14} \mathrm{C}\right]$ rucaparib in medium containing $7.5 \mu \mathrm{l} \mathrm{ml}^{-1}\left[{ }^{3} \mathrm{H}\right]$ sucrose/inulin (Amersham International, GE Healthcare, Amersham, UK) and $100 \mu$ l layered onto $100 \mu \mathrm{l}$ silicone oil (9:11 Dow Corning 556 (Sp. Gr. 0.98): Dow Corning 550 (Sp. Gr. 1.068), final Sp. Gr. 1.028; BDS, Poole, UK) overlaying $50 \mu \mathrm{l} 3 \mathrm{M} \mathrm{KOH}$ in 3 replicate $0.5 \mathrm{ml}$ microfuge tubes at intervals for up to 2 or $1 \mathrm{~h}$ in the presence of ouabain (30 or $100 \mu \mathrm{M}$ ), cytochalasin B $(0.1$ or $1 \mu \mathrm{M})$, dipyridamole $(10$ or $100 \mu \mathrm{M})$ or $\mathrm{BCH}$ ( 1 or $2 \mathrm{~mm}$ ), or in transport buffer $(130 \mathrm{~mm} \mathrm{NaCl}, 5 \mathrm{~mm} \mathrm{KCl}, 1 \mathrm{~mm}$ $\mathrm{MgCl}_{2}, 5 \mathrm{~mm} \mathrm{NaH}{ }_{2} \mathrm{PO}_{4}, 10 \mathrm{~mm}$ glucose and $10 \mathrm{~mm}$ HEPES, pH 7.4) where the $\mathrm{NaCl}$ was replaced with choline chloride. The tubes were immediately centrifuged at $12000 \mathrm{~g}$ for $2 \mathrm{~min}$ at room temperature causing the cells to pass through the oil and into the $\mathrm{KOH}$. After centrifugation, the tubes were capped and cut in the oil layer such that the bottom portion (cells solubilised in $\mathrm{KOH}$ ) fell into a $20-\mathrm{ml}$ scintillation vial. To disperse and neutralise the $\mathrm{KOH} 1 \mathrm{ml}$ of $0.25 \mathrm{M}$ acetic acid was injected into the tube and, following the addition of $10 \mathrm{ml}$ of Optiphase HiSafe scintillant (Fischer Chemicals, Loughborough, UK), the radioactivity was determined by a dual-label assay using an LKB-Wallac S1410 $\beta$-counter (Wallac, Croydon, UK). Cell volume was calculated in a similar manner using $\left[{ }^{3} \mathrm{H}\right] \mathrm{H}_{2} \mathrm{O}$ and $\left[{ }^{14} \mathrm{C}\right]$ sucrose to be $1.79 \pm 0.29 \mu \mathrm{l}$ per $10^{6}$ cells and this value, along with the cell count, was used to calculate the intracellular concentration of drug by reference to the original mixture of $400 \mathrm{~nm}\left[{ }^{14} \mathrm{C}\right]$ rucaparib $+7.5 \mu \mathrm{ml}^{-1}\left[{ }^{3} \mathrm{H}\right]$ sucrose/inulin. To determine the kinetics of uptake, SW620 cells were exposed to increasing concentrations of $\left[{ }^{14} \mathrm{C}\right]$ rucaparib $(0-80 \mu \mathrm{M})$ plus $\left[{ }^{3} \mathrm{H}\right]$ sucrose for $30 \mathrm{~min}$ and the intracellular concentration was determined as above. To measure the retention of drug, cells were incubated with $\left[{ }^{14} \mathrm{C}\right]$ rucaparib for $30 \mathrm{~min}$ then washed and transferred to fresh medium, and the intracellular $\left[{ }^{14} \mathrm{C}\right]$ rucaparib concentration was determined as above. To determine the retention over extended periods, cells $\left(5 \times 10^{5}\right.$ cells for incubations of up to $24 \mathrm{~h}$ and $2 \times 10^{5}$ cells for longer incubations) were seeded into six-well plates and allowed to attach overnight. They were then exposed to $400 \mathrm{~nm}\left[{ }^{14} \mathrm{C}\right]$ rucaparib $+7.5 \mu \mathrm{ml} \mathrm{l}^{-1}\left[{ }^{3} \mathrm{H}\right]$ sucrose/ inulin for $30 \mathrm{~min}$ prior washing three times with $\mathrm{PBS}$ and solubilising immediately with $0.2 \mathrm{M} \mathrm{KOH}$ or incubated with fresh medium for up to $72 \mathrm{~h}$ before solubilising with $0.2 \mathrm{M} \mathrm{KOH}$. Samples were neutralised with acetic acid, mixed with scintillant and counted as above. In parallel with these studies, SW620 cells were exposed to $400 \mathrm{~nm}$ rucaparib for $30 \mathrm{~min}$ then either immediately washed three times with PBS, harvested by trypsinisation, resuspended in $1 \mathrm{ml}$ medium $+10 \%$ DMSO and frozen at $-80^{\circ} \mathrm{C}$, or washed and re-incubated with fresh medium for up to $72 \mathrm{~h}$ before harvesting and cryopreserving, such that all samples could be assayed for PARP activity together.

Cytotoxicity assays. Exponentially growing Capan-1 cells and MX-1 cells were seeded at low density (500-2000 per well 
for control and up to 10000 per well for rucaparib treatment) in six-well dishes. After $18-24 \mathrm{~h}$, they were exposed to increasing concentrations of rucaparib $(0-50 \mu \mathrm{M})$ for $24 \mathrm{~h}$ before replacement with drug-free medium. After 10-14 days, colonies were stained with $0.4 \%$ crystal violet, were counted and survival relative to control was calculated.

Establishment of Capan-1 and MX-1 xenografts. All experiments involving mice were reviewed and approved by the relevant institutional animal welfare committee and performed according to the UK Coordinating Committee on Cancer Research Guidelines for the Welfare of Animals in Experimental Neoplasia and UK law. Female CD-1 nude mice aged 10-12 weeks (Charles River laboratories, Wilmington, MA, USA) maintained and handled in isolators under specific pathogen-free conditions, with 5 mice per cage and 20 cages per isolator) were used in all xenograft experiments. $10^{7}$ exponentially growing Capan-1 cells in $50 \mu \mathrm{l}$ of phosphate-buffered saline were implanted into one site on the right flank of each mouse. Exponentially growing MX-1 cells $\left(2 \times 10^{6}\right.$ cells per mouse) were implanted in a 1:1 mix of growth factor reduced, basement membrane Matrigel matrix (BD Biosciences, Oxford, UK), and medium.

Rucaparib plasma pharmacokinetics and tissue distribution. Rucaparib was dissolved in sterile deionised water to give a final concentration such that mice would receive the appropriate dose in $250-300 \mu$ l by the i.p. route or $375-450 \mu$ l by the oral route. A single dose of rucaparib $\left(10 \mathrm{mg} \mathrm{kg}^{-1}\right.$ i.p. or 50,100 or $150 \mathrm{mg} \mathrm{kg}^{-1}$ p.o.) was administered to CD-1 nude mice bearing established ( $\geqslant 5 \times 5 \mathrm{~mm}$ ) Capan-1 xenografts (18 mice per group), and at $0.5,4,24,48,72$ and $168 \mathrm{~h}$ three mice per group were bled by cardiac puncture under general anaesthesia and then killed. The brains and tumours were removed, were snap frozen in liquid nitrogen and were stored at $-80^{\circ} \mathrm{C}$ before analysis. Plasma was derived from the blood samples using standard methods and was stored at $-80{ }^{\circ} \mathrm{C}$. Three untreated control animals were processed equivalently. Similarly, mice bearing MX-1 xenografts were given a single dose of rucaprib i.p. (50 $\left.\mathrm{mg} \mathrm{kg}^{-1}\right)$ or orally $\left(150 \mathrm{mg} \mathrm{kg}^{-1}\right)$, and tumours and livers were harvested and snap frozen $24 \mathrm{~h}$ later. In a satellite study, murine PBMCs were harvested as previously described (Plummer et al, 2008) in parallel with collection of plasma $30 \mathrm{~min}, 6$ and $24 \mathrm{~h}$ after a single dose of rucaparib (10 $\mathrm{mg} \mathrm{kg}^{-1}$ i.p.). To obtain sufficient volume for lymphopreparation, blood was pooled from three mice per sample.

Brain, liver and tumour samples were homogenised 1 in $4(\mathrm{w} / \mathrm{w})$ in isotonic buffer $(7 \mathrm{~mm}$ HEPES, $26 \mathrm{~mm} \mathrm{KCl}, 0.1 \mathrm{~mm}$ dextran, $0.4 \mathrm{~mm}$ EGTA, $0.5 \mathrm{~mm} \mathrm{MgCl}_{2}$ and $45 \mathrm{~mm}$ sucrose ( $\mathrm{pH} 7.8$ )) using a PRO Scientific 2000 hand held homogeniser (Pro Scientific, Inc., Monroe, CT, USA). Samples were analysed using a Waters Alliance 2690 (Waters Corporation, Milford, MA, USA) HPLC, coupled with a Waters 996 Photo Diode Array detector and Aglient (Wokingham, UK) 1200 fluorescent detector. Waters Empower 2 software (Waters Corporation) was used to control the instrument. Samples and standards were precipitated with acetonitrile (HPLC grade; Fischer Scientific, Loughborough, UK), the supernatant evaporated to dryness under nitrogen then reconstituted in mobile phase and $50 \mu \mathrm{l}$ was analysed using a Supelcosil LC-CN $5 \mu \mathrm{m} 25 \mathrm{~cm} \times 4.6$ column (Sigma-Aldrich, Supelco, Gillingham, UK) with a Security guard C18 ODS $4 \mathrm{~mm} \times 3 \mathrm{~mm}$ precolumn (Phenomenex, Cheshire, UK). A mobile phase of $0.02 \mathrm{M} \mathrm{Na}$ formate, $\mathrm{pH} 3.5$, in acetonitrile $(1: 1 \mathrm{v} / \mathrm{v})$ was used with a flow rate of $1 \mathrm{ml} \mathrm{min}{ }^{-1}$. Plasma concentrations of rucaparib and the carboxy metabolite were determined by reference to standards prepared in human plasma with fluorescence detection ( $\lambda$ ex 238/ $\lambda \mathrm{em} 470 \mathrm{~nm}$ ).

Rucaparib efficacy study. Mice bearing Capan-1 or MX-1 xenografts were randomly assigned to treatment groups (described in the Results section) once they had palpable tumours (i.e., $\geqslant 5 \times 5 \mathrm{~mm}$ ). Mice were weighed and tumour volumes were determined three times per week from two-dimensional calliper measurements and the equation $a^{2} \times b / 2$ (where $a=$ width and $b=$ length of the tumour). Tumour data are presented as the dimension-less parameter, relative tumour volume (RTV). For example, RTV1 is the tumour volume on the first day of treatment (day 0), RTV2, 3 and 4 are when the tumours are 2, 3 or 4 times larger than RTV1. Mice bearing tumours that had grown to $10 \times 10 \mathrm{~mm}$ or $>15 \mathrm{~mm}$ in any dimension, or showing signs of stress, were humanely killed.

Poly(ADP-ribose) polymerase-1 activity. In parallel with the $\left[{ }^{14} \mathrm{C}\right]$ rucaparib retention studies, the PARP activity was determined following a 30 -min exposure to $400 \mathrm{~nm}$ rucaparib in exponentially growing SW620 cells and also in Capan-1 and MX-1 cells after a 30 -min pulse exposure to $400 \mathrm{~nm}$ rucaparib. Poly(ADP-ribose) polymerase- 1 activity was also measured in mouse PBMCs, and brain, liver and tumour homogenates at various times after administration of rucaparib at various doses and routes using a validated assay as previously described (Plummer et al, 2005; Daniel et al, 2010). Tissues were homogenised in 3 volumes of isotonic buffer then further diluted in isotonic buffer ( $1: 3000$ final dilution for brain and 1:20000 final dilution for tumour) immediately before determining the PARP activity. In brief, PARP activity in 500 permeabilised cells per PBMCs or $50 \mu \mathrm{l}$ of tissue homogenate was maximally stimulated with a double-stranded oligonucleotide in the presence of excess NAD $(350 \mu \mathrm{M})$ and the amount of ADP-ribose polymer formed quantified by immunoblot using anti-PAR antibody (clone $10 \mathrm{H}$, from Professor Dr Alex Burkle University of Konstanz) by reference to a PAR standard curve (Enzo Life Sciences, Exeter, UK). Data are expressed as pMol PAR per $10^{6}$ cells by reference to cell counts or pMol per mg protein by reference to protein assay of the homogenate (Pierce assay; Thermo Scientific, Leicestershire, UK).

\section{RESULTS}

Rucaparib accumulation and PARP inhibition in cells. Following exposure of SW620 cells to $400 \mathrm{nM}{ }^{14} \mathrm{C}$ rucaparib the intracellular concentration rose to $>10 \mu \mathrm{M}$, with steady-state levels being achieved by $30 \mathrm{~min}$ (Supplementary Figure 1A). We then investigated the mechanism by which it accumulated: uptake followed Michaelis-Menten kinetics with a $\mathrm{Km}=8.4 \pm 1.2 \mu \mathrm{M}$ and $\mathrm{Vmax}$ of $469 \pm 22$ pmol per $10^{6}$ cells per $10 \mathrm{~min}$ (mean and s.d. of three independent experiments), indicating that it was carrier mediated (Figure 1A). Ouabain had only a very modest effect on uptake (Figure 1B) and replacement of the sodium buffer with a potassium buffer reduced uptake slightly but replacement of sodium with choline had no effect (Supplementary Figure 1B), suggesting that the contribution of the $\mathrm{Na}+/ \mathrm{K}+$ ATPase was minimal. Similarly, the glucose transporter was not implicated as cytochalasin B had no effect on uptake and neither the nucleoside transport inhibitor, dipyridamole, nor the amino-acid transport inhibitor, $\mathrm{BCH}$, inhibited accumulation (Figure 1C-E). The transporter responsible remains to be identified. Efflux of rucaparib after a 30-min pulse with $400 \mathrm{~nm}$ was biphasic with up to $50 \%$ being lost in the first 5-10 min followed by very slow efflux over the next $110 \mathrm{~min}$ such that concentrations at $2 \mathrm{~h}$ after removal of drug were still $>10 \times$ higher than the original extracellular concentration (Figure 1C). Measurement of the intracellular rucaparib for $24 \mathrm{~h}$ after removal of drug revealed that there was an exponential decline in the concentration with a half-life of $20 \mathrm{~min}$. Parallel studies measuring PARP activity over $24 \mathrm{~h}$ after drug removal revealed that PARP was inhibited for this period (Supplementary Figure 1C), indeed in a further experiment it was still only $35 \pm 12 \%(n=3)$ of control 

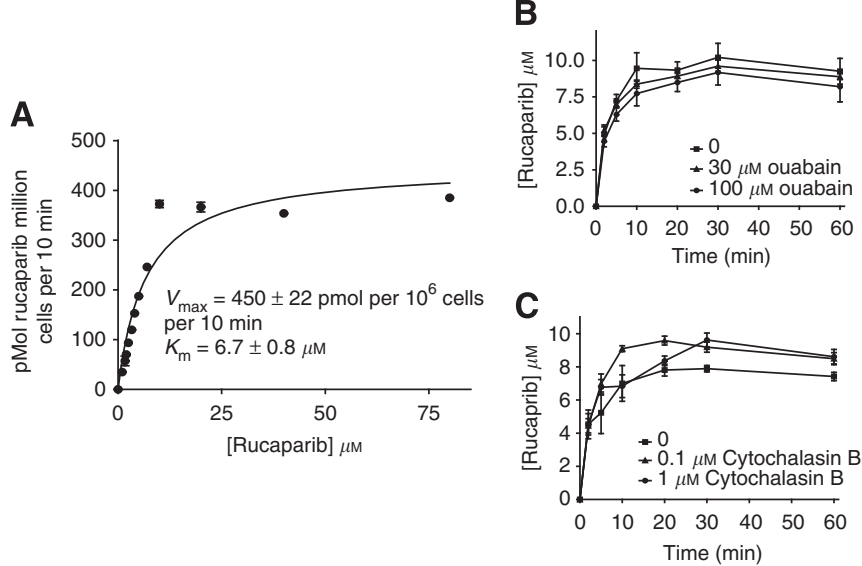

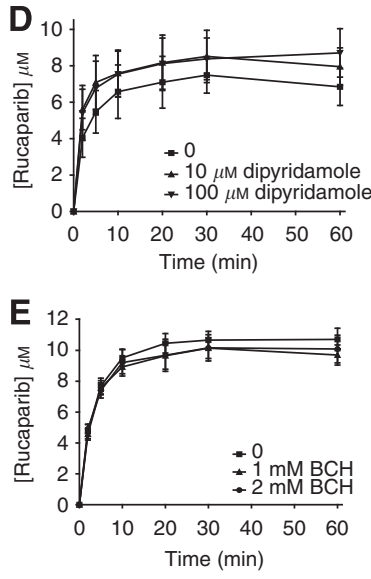

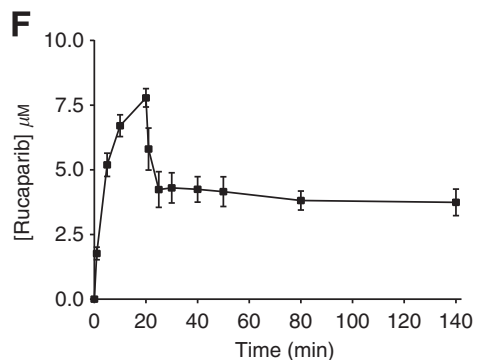

Figure 1. The accumulation and retention of $\left[{ }^{14} \mathrm{C}\right]$ rucaparib, associated durable PARP inhibition in human cancer cell lines and cytotoxicity to BRCA 1 and 2 mutant cells. (A) Michaelis-Menten kinetics of rucaparib accumulation in SW620 cells, exposed to increasing rucaparib concentrations for 30 min before determination of intracellular concentration data are for a single representative experiment. (B-E) Rucaparib accumulation in the presence of various transporter inhibitors: $\mathrm{Na}+/ \mathrm{K}+$ ATPase inhibitor Ouabain at 30 and $100 \mu \mathrm{M}$ (B); the glucose transport inhibitor, cytochalasin B at 0.1 and $1 \mu \mathrm{M}(\mathbf{C})$; the nucleoside transport inhibitor, dipyridamole at 10 and $100 \mu \mathrm{m}$ (D); and the amino-acid transport inhibitor $\mathrm{BCH}$ at 1 or $2 \mathrm{~mm}$ (E). (F) Time course of uptake and retention of $\left[{ }^{14} \mathrm{C}\right]$ rucaparib in $\mathrm{SW} 620$ cells exposed to $400 \mathrm{~nm}\left[{ }^{14} \mathrm{C}\right] \mathrm{rucaparib}$ for $20 \mathrm{~min}$ before washing and incubating in fresh medium for a further $2 \mathrm{~h}$, data are from triplicate estimations in a single representative experiment.
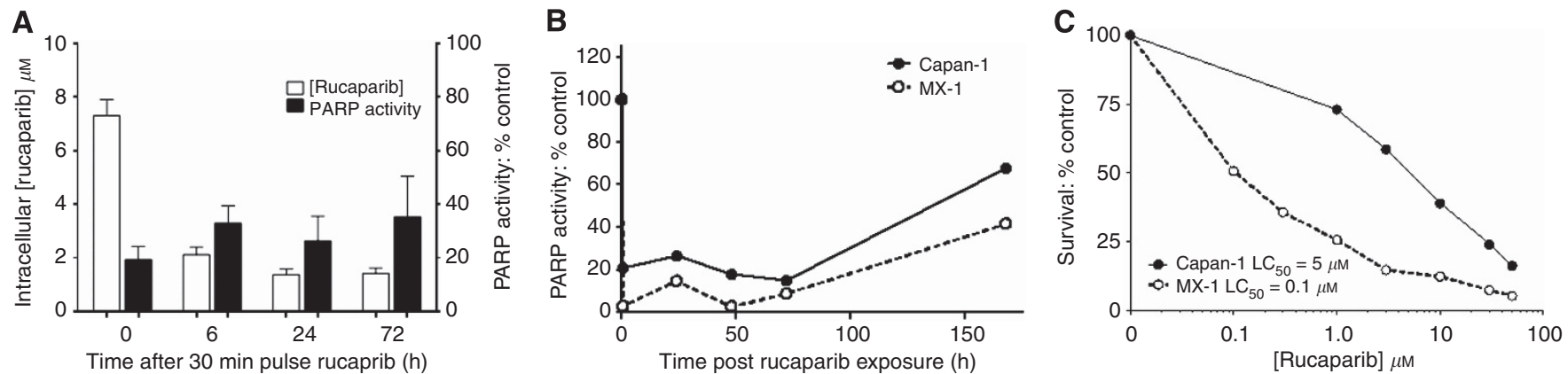

Figure 2. Durability of PARP inhibition following a short pulse of rucaparib. (A) Parallel measurements of rucaparib retention and PARP inhibition in SW620 cells for up to 3 days following a 30-min exposure to $400 \mathrm{~nm}\left[{ }^{14} \mathrm{C}\right]$ rucaparib, followed by transfer to drug-free medium. Data are mean and s.e.m. from three independent experiments. (B) Poly(ADP-ribose) polymerase-1 inhibition in Capan-1 and MX-1 cells for up to 7 days after exposure to a 30-min pulse of $400 \mathrm{~nm}$ rucaparib, data are from a single representative experiment. (C) Survival of Capan-1 (BRCA2 mutant) and MX-1 (BRCA1 mutant) cells following $24 \mathrm{~h}$ exposure to increasing concentrations of rucaparib then transfer to fresh medium for colony formation, data are mean of two independent experiments.

activity at $72 \mathrm{~h}$ (Figure 2A). Further studies in Capan-1 and MX-1 cells revealed that PARP inhibition persisted for $72 \mathrm{~h}$ after a 30 -min pulse with $400 \mathrm{~nm}$ rucaparib in these cells too and that PARP activity was still below baseline 1 week after drug removal (Figure 2B). Rucaparib was cytotoxic in these cells with the $\mathrm{LC}_{50}$ being $5 \mu \mathrm{M}$ in Capan- 1 cells and only $100 \mathrm{~nm}$ in MX-1 cells (Figure 2C), which is in line with our previous studies of rucaparib in Capan-1 cells (Drew et al, 2011) and previous reports of the differential cytotoxicity of PARPi in these cells (Shen et al, 2013).

Rucaparib pharmacokinetics and tissue distribution in tumourbearing mice. Mice bearing Capan-1 tumours were given a single administration of rucaparib either by the i.p. route at a dose of $10 \mathrm{mg} \mathrm{kg}^{-1}$, the dose previously shown to be active in repeated dosing schedule (Drew et al, 2011), or orally at 50, 100 or $150 \mathrm{mg} \mathrm{kg}^{-1}$. Parent drug was detectable in the plasma only at $30 \mathrm{~min}$ after $10 \mathrm{mg} \mathrm{kg}^{-1}$ i.p and up to $4 \mathrm{~h}$ for $50-150 \mathrm{mg} \mathrm{kg}^{-1}$ p.o. in all three mice per group (Figure $3 \mathrm{~A}$ ). At $24 \mathrm{~h}$, one mouse in the $100 \mathrm{mg} \mathrm{kg}^{-1}$ group and at $48 \mathrm{~h}$ one mouse in the $150 \mathrm{mg} \mathrm{kg}^{-1}$ group had detectable levels of parent drug. Rucaparib reached higher concentrations in the tumour, such that levels were up to $10 \times$ the plasma concentration at $4 \mathrm{~h}$. The drug was retained in tumour for longer than in plasma, and although levels were much lower than at earlier time points, rucaparib was still detectable in most mice receiving oral rucaparib at 3 days (Figure 3B). Uptake into the brain was $\leqslant 10 \%$ of plasma concentrations (Figure $3 \mathrm{C}$ ). A metabolite was detected, identified as 4-(8-fluoro-6-oxo-3,4, 5,6-tetrahydro- $1 \mathrm{H}$-azepino[5,4,3-cd]indol-2-yl)benzoic acid, that reached higher concentrations than the parent drug in the plasma, but lower in the tumour (Supplementary Figure 2A and B). Experiments to determine PARP inhibition by this compound showed that when added to permeabilised cells it inhibited PARP activity with an $\mathrm{IC}_{50}$ of $\sim 550 \mathrm{nM}$; however, pre-incubation of intact cells with the compound did not result in PARP inhibition, suggesting that it does not easily cross the plasma membrane (Supplementary Figure 2C). There was some suggestion of a modest cumulative effect in that PARP activity was suppressed by $71 \pm 3 \%$ $(n=3)$ in tumours $24 \mathrm{~h}$ after a single p.o. dose of $150 \mathrm{mg} \mathrm{kg}^{-1}$ and by $79 \pm 0.6 \%(n=3) 24 \mathrm{~h}$ after the third weekly dose, but this was not significant $(P=0.0589)$ (Supplementary Table 1$)$. 


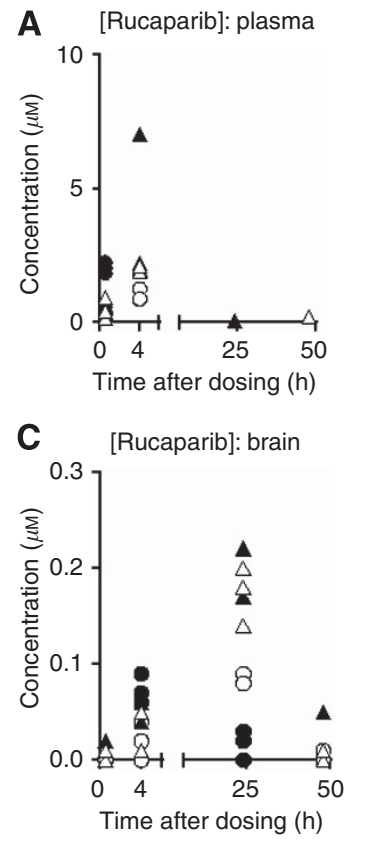

B

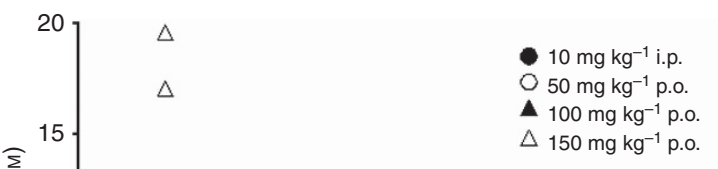

Figure 3. Pharmacokinetics of rucaparib in Capan-1 tumour-bearing mice. Concentrations of rucaparib in plasma (A), tumour (B) and brain (C) at various times up to 1 week after a single dose of rucaparib either $10 \mathrm{mg} \mathrm{kg}^{-1}$ i.p. (filled circles) $50 \mathrm{mg} \mathrm{kg}^{-1}$ p.o. (open circles), $100 \mathrm{mg} \mathrm{kg}{ }^{-1}$ p.o. (filled triangles) or $150 \mathrm{mg} \mathrm{kg}^{-1}$ p.o. (open triangles). Data are individual values from three mice per group.
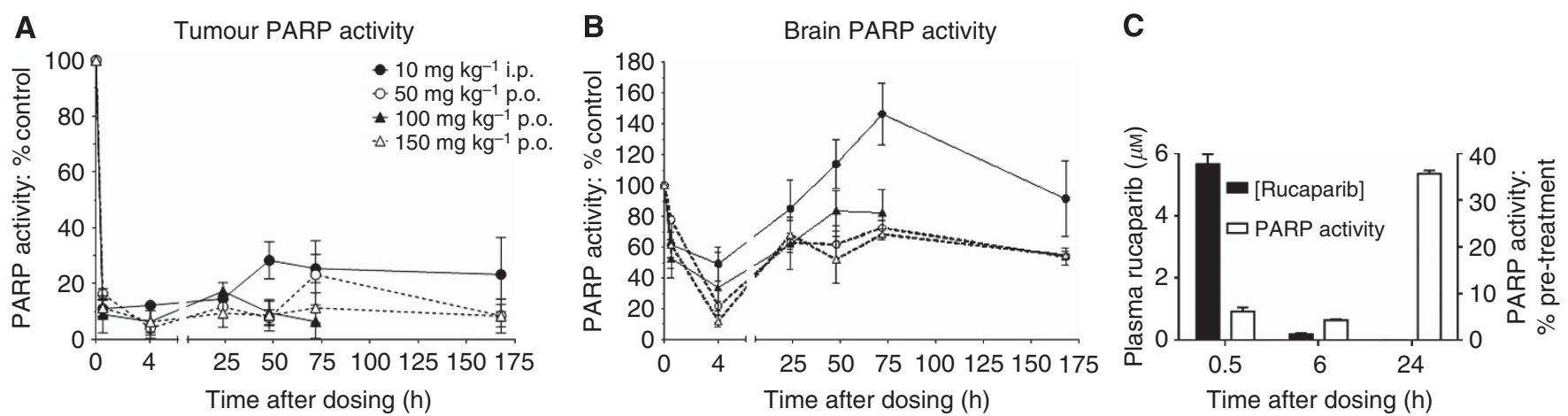

Figure 4. Poly(ADP-ribose) polymerase-1 activity in tumour, brain and PBMCs following a single dose of rucaparib. Poly(ADP-ribose) polymerase-1 activity was determined in homogenates of Capan-1 tumours and brains of mice at various times up to 1 week after a single dose of rucaparib either $10 \mathrm{mg} \mathrm{kg}^{-1}$ i.p. (filled circles) $50 \mathrm{mg} \mathrm{kg}^{-1}$ p.o. (open circles), $100 \mathrm{mg} \mathrm{kg}^{-1}$ p.o. (filled triangles) or $150 \mathrm{mg} \mathrm{kg}^{-1}$ p.o. (open triangles).

Data are mean \pm s.e.m. from three mice per group. (C) Plasma rucaparib levels and PARP activity in PBMCs were determined following a single injection of rucaparib $\left(10 \mathrm{mg} \mathrm{kg}^{-1}\right.$ i.p.). Data are mean \pm s.e.m. from three mice per time point (PBMC triplicates from pooled blood of three mice per time point).

Persistence of tumour PARP inhibition. In parallel with the PK study, PARP activity was determined in tumour and brain tissue. Poly(ADP-ribose) polymerase- 1 activity in the tumours was reduced to $<20 \%$ of baseline between $30 \mathrm{~min}$ and $24 \mathrm{~h}$ after all doses and routes of administration (Figure 4A). Poly(ADP-ribose) polymerase-1 activity showed a modest recovery to $\sim 30 \%$ of baseline after $48 \mathrm{~h}$ in mice receiving rucaparib at $10 \mathrm{mg} \mathrm{kg}^{-1}$ i.p., but showed no further recovery over the subsequent 4 days. Following oral dosing, there appeared to be no substantial recovery in PARP activity for the entire monitoring period following a single dose and PARP activity in mice receiving both 50 and $150 \mathrm{mg} \mathrm{kg}^{-1}$ was still $\sim 10 \%$ of control at 7 days. As expected from the much lower drug concentrations achieved in the brain, PARP inhibition in brain tissue was more modest. Following the single $10 \mathrm{mg} \mathrm{kg}^{-1}$ i.p. dose PARP was initially inhibited by about $50 \%$, but activity recovered to baseline levels between 24 and $48 \mathrm{~h}$ with some indication of a stimulation of PARP activity at 3 days before return to normal at 7 days. Following oral dosage, there was a $>60 \%$ reduction in PARP activity at $4 \mathrm{~h}$ followed by a recovery to $\sim 70-80 \%$ of baseline, but activity was still suppressed at 7 days (Figure 4B). In a satellite PK/PD study, plasma rucaparib and $\mathrm{PARP}$ in PBMCs were measured for up to $24 \mathrm{~h}$ after a single dose of rucaparib $\left(10 \mathrm{mg} \mathrm{kg}^{-1}\right.$ i.p.). Plasma rucaparib concentrations were similar to those in the main study, and although profound suppression of PARP activity was observed up to $6 \mathrm{~h}$ postadministration it had recovered to between 35 and $40 \%$ of control by $24 \mathrm{~h}$ (Figure $4 \mathrm{C}$ ).

Efficacy of rucaparib on weekly and daily schedules. In view of the marked persistence of PARP inhibition by rucaparib, we investigated different schedules of administration. Mice bearing Capan-1 xenografts were randomised (10 mice per group) when tumours were $\geqslant 5 \times 5 \mathrm{~mm}$ to receive vehicle control; rucaparib at $10 \mathrm{mg} \mathrm{kg}^{-1}$ i.p. daily for 5 days per week for 6 weeks (daily $\times$ five 


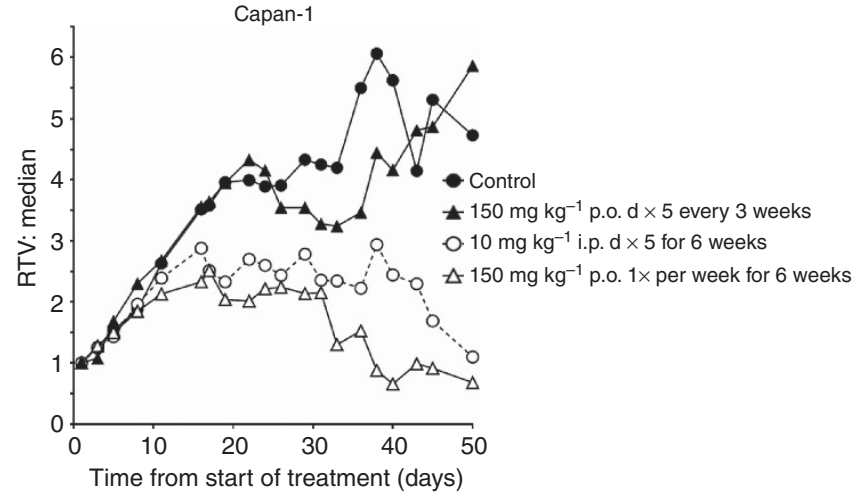

Figure 5. Efficacy of different schedules of rucaparib against Capan-1 tumours. Median tumour volume RTV in mice treated with vehicle alone (saline; filled circles) or rucaparib $10 \mathrm{mg} \mathrm{kg}^{-1}$ i.p. daily five times for 6 weeks (open circles), or $150 \mathrm{mg} \mathrm{kg}^{-1}$ p.o. once per week for 6 weeks (filled triangles) or $150 \mathrm{mg} \mathrm{kg}^{-1}$ p.o. daily five times every 3 weeks. Data are median from eight mice per group.

\begin{tabular}{|c|c|c|}
\hline Treatment & $\begin{array}{l}\text { Complete } \\
\text { regressions }\end{array}$ & $\begin{array}{l}\text { Mice remaining } \\
\text { at day } 40\end{array}$ \\
\hline Vehicle control & $0 / 10$ & $3^{a}$ \\
\hline $10 \mathrm{mg} \mathrm{kg}^{-1}$ i.p., $\mathrm{d} \times 5 \mathrm{w} \times 6$ & $1 / 10$ & 6 \\
\hline $50 \mathrm{mg} \mathrm{kg}^{-1}$ p.o., $d \times 5 w \times 6$ & $0 / 10$ & 2 \\
\hline $150 \mathrm{mg} \mathrm{kg}^{-1}$ p.o., $\mathrm{d} \times 5 \mathrm{w} \times 6$ & $1 / 10$ & 5 \\
\hline $150 \mathrm{mg} \mathrm{kg}^{-1}$ p.o., $1 \times w \times 6$ & $3 / 10$ & 7 \\
\hline $150 \mathrm{mg} \mathrm{kg}^{-1}$ p.o., $3 \times w \times 6$ & $1 / 10$ & 5 \\
\hline $150 \mathrm{mg} \mathrm{kg}^{-1}$ p.o., dx5 every $3 \mathrm{w}$ & $1 / 10$ & 5 \\
\hline
\end{tabular}

weekly $\times$ six), as this was a schedule previously shown to be effective (Drew et al, 2011); 50 or $150 \mathrm{mg} \mathrm{kg}^{-1}$ p.o. daily $\times$ five weekly $\times$ six as a direct comparison with the i.p. schedule; $150 \mathrm{mg} \mathrm{kg}^{-1}$ p.o. once per week for 6 weeks or three times per week for 6 weeks to investigate intermittent schedules, or $150 \mathrm{mg} \mathrm{kg}$ p.o. daily for five days every 3 weeks to mimic the schedule originally given to BRCA mutation carrier patients with breast or ovarian cancer (NCT00664781). Tumours grew more slowly than we had previously observed: median time to quadruple in volume (RTV4) being 22 days (11.5 days, previously). However, it should be noted that mice in all groups had to be killed from day 22 onwards because of tumour burden, and by day 40 there were only three mice remaining in the control group (Table 1). Rucaparib at $10 \mathrm{mg} \mathrm{kg}^{-1}$ i.p. significantly $(P=0.0005$, MannWhitney test) inhibited the growth of the tumour such that RTV4 was not reached during the 50-day trial (Figure 5), and there was one complete tumour regression and two persistent partial regressions. Daily oral administration of rucaparib at $150 \mathrm{mg} \mathrm{kg}^{-1}$ had an equivalent effect on tumour growth to $10 \mathrm{mg} \mathrm{kg}^{-1}$ i.p. (Supplementary Figure 3A). However, the schedule with the greatest antitumour effect $(P<0.00001)$ was oral administration of $150 \mathrm{mg} \mathrm{kg}^{-1}$ on a once weekly schedule with three complete regressions (Figure 5, Table 1). The other dosing schedules, including the daily for five days every 3 weeks schedule, analogous to the original clinical schedule, had only marginal effect on tumour growth that was not significant $(P=0.3720)$ Figure 5 and Supplementary Figure 3A). There was no significant weight loss on any of the schedules (Supplementary Figure 3B).

As the MX-1 cells were around 50 times more sensitive to rucaparib cytotoxicity in vitro, we hypothesised that MX-1 xenografts would respond well to rucaparib administration. Pilot studies suggested that these cells only established well in nude mice if implanted in Matrigel. Fewer mice developed tumours and they were randomised to the following groups (7-8 mice per group) when tumours were $\geqslant 5 \times 5 \mathrm{~mm}$ : vehicle control; rucaparib at $10 \mathrm{mg} \mathrm{kg}^{-1}$ i.p. daily five times weekly for 6 weeks; rucaparib at $50 \mathrm{mg} \mathrm{kg}^{-1}$ i.p. once weekly for 6 weeks; or rucaparib at $150 \mathrm{mg} \mathrm{kg}^{-1}$ p.o. once weekly for 6 weeks. Despite the Matrigel, tumours grew slowly only doubling in size after 30 days, and tumour growth was not delayed in any of the rucaparib treatment groups (Supplementary Figure 3C). Rucaparib did not cause any significant weight loss in the mice $(\leqslant 4 \%$ weight loss at nadir, Supplementary Figure S3D). Formal PK-PD studies were not conducted with this xenograft, but in a pilot study PARP was inhibited by $>80 \% 24 \mathrm{~h}$ after a single dose of $150 \mathrm{mg} \mathrm{kg}^{-1}$ p.o. and $>55 \%$ after $50 \mathrm{mg} \mathrm{kg}^{-1}$ i.p. in the tumours but not in the livers from these mice, indicating a tumour-specific effect (Supplementary Figure 3E). In additional satellite studies, PARP was inhibited by $87-92 \% 3$ days after $150 \mathrm{mg} \mathrm{kg}^{-1}$ but only $44-74 \% 7$ days after $150 \mathrm{mg} \mathrm{kg}^{-1}$. Interestingly in this study MX-1 tumours were found to have 3-4 times higher PARP activity than Capan- 1 tumours, such that at 7 days after rucaparib the levels in the MX-1 tumours were comparable to those in Capan-1 tumours from untreated mice (Supplementary Figure S3F).

\section{DISCUSSION}

Rucaparib is a potent PARPi that has been undergoing clinical evaluation since 2003. Evidence from studies of the pharmacodynamic effect of rucaparib in patients suggested that it caused durable PARP inhibition (Plummer et al, 2005). The aim of the current study was to identify if this was the case to explore the mechanisms and to see if this was exploitable using intermittent dosing regimens. We found that rucaparib uptake into cells displays saturable, classic Michaelis-Menten kinetics, indicating that it is carrier mediated. It is possible that uptake is by a carrier that would normally transport nicotinamide, as rucaparib, like most PARPi, contains a nicotinamide pharmacophore. Transport of nicotinamide and its metabolites is poorly defined; early studies suggested that uptake of nicotinamide was via the glucose transporter (Sofue et al, 1992), but more recent data suggest that nicotinamide riboside is the extracellular $\mathrm{NAD}^{+}$ precursor and that this enters via the nucleoside transporter (Nikiforov et al, 2011). Our data indicate that neither the glucose nor nucleoside transporters were responsible for the uptake of rucaparib. The amino-acid carrier was also excluded and uptake appeared to be sodium independent. Rucaparib accumulated in cells against a concentration gradient, suggesting either that uptake was energy driven or once inside the cell rucaparib was rapidly sequestered or bound to cellular protein. The accumulation of rucaparib into PARP-1 null MEFs was similar to that of their wildtype counterparts (data not shown); thus, it seems unlikely that accumulation is driven by binding to PARP-1. Associated with the cellular accumulation and retention, we found that PARP activity was inhibited by $\geqslant 70 \%$ in all three cell lines for at least $72 \mathrm{~h}$ after a 30 -min pulse and, where measured, PARP activity was still $\geqslant 30 \%$ below baseline 1 week after initial exposure. We do not believe this is analogous to trapping of PARP-1 on DNA (Satoh and Lindahl, 1992; Murai et al, 2012) because we were able to measure PARP 
inhibition in PBMCs from patients receiving rucaparib even after they had been subjected to lymphopreparation and cryopreservation prior to ex vivo stimulation of PARP activity by an oligonucleotide mimicking DNA breaks in the presence of $350 \mu \mathrm{M} \mathrm{NAD}{ }^{+}$. Together, these observations and the data presented here, coupled with the Ki $(1.4 \mathrm{nM})$ for rucaparib being $<1 / 50$ th of the $\mathrm{Km}$ for $\mathrm{NAD}^{+}$(estimated range from 75 to $200 \mu \mathrm{M}$ ), which suggest avid binding of rucaparib to the enzyme.

Rucaparib was also retained in tumour xenografts after it had been cleared from the plasma, similar to our previous observations with the related inhibitor, AG14361 (Calabrese et al, 2004). Most remarkably, PARP activity was inhibited in tumour xenografts for 1 week after a single injection. There is some suggestion that this might be a tumour-specific effect, as PARP activity in the liver appeared to have recovered completely within $24 \mathrm{~h}$ and there was a $>35 \%$ recovery in PBMC PARP activity at this time. Haematological toxicities have been reported clinically with PARPi, particularly when administered with cytotoxic drugs (Do and Chen, 2013). Further studies are warranted to determine whether careful scheduling may allow the cytotoxic to be administered when PARP activity has recovered in normal tissues but remains inhibited in the tumour, thereby increasing the therapeutic window. As with the in vitro uptake studies, the mechanism by which rucaparib is taken up into and retained within the tumour remains to be elucidated. There was some suggestion of a cumulative effect in the tumours with repeated dosing, but further studies following repeated daily or weekly dosing would be required to confirm whether this effect was likely to be of clinical relevance.

The oral bioavailability of rucaparib was similar to that in humans (Shapiro et al, 2013) but with a more rapid elimination from plasma. The measured concentrations varied widely between animals. However, there was apparent dose linearity, consistent with clinical data. The carboxylic acid metabolite, although it accumulates to levels comparable to those of the parent drug, does not seem to contribute to the PARP inhibitory activity. In vivo studies show only a very modest uptake of rucaparib into the brain reducing the likelihood of cognitive/neurological side effects. Many drugs are excluded from the brain by virtue of the blood-brain barrier, which is in part attributable to the $\mathrm{ABC}$ drug efflux transporters (reviewed in Deeken and Loscher, 2007) but, as in vitro data showing the accumulation of rucaparib argue against it being a substrate for $\mathrm{ABC}$ transporters, unlike olaparib (Dedes et al, 2011), the mechanism of exclusion from the CNS is not known.

The in vivo efficacy study in mice bearing Capan-1 xenografts confirmed our previous finding that $10 \mathrm{mg} \mathrm{kg}^{-1}$ once a day for 5 days per week for 6 weeks significantly inhibited tumour growth with both complete and partial regressions. For the first time, we show that a weekly schedule of a PARPi has significant antitumour activity. A single administration of rucaparib once weekly was at least as effective as daily administration, with three complete regressions on this schedule, consistent with the prolonged PARP inhibition after a single dose. The use of tumour xenografts does, of course, have its limitations, and Capan-1 subcutaneous xenografts do not model closely to the pathology of pancreatic tumours in humans, where there is a large stromal component. Nevertheless, the first clinical trials of single-agent PARPi were initiated following promising xenograft studies with mutant or genetically engineered murine cells, and have been sufficiently successful to result in pre-registration trials being conducted with four different PARPi. Disappointingly, there was no antitumour activity of rucaparib in the MX-1 xenografts, this may have been because of the slow growth of the tumours. Other studies using xenotransplantation report much faster growth of MX-1 xenografts (Shen et al, 2013). Whether the method of implantation of the tumour or insufficient potency of rucaparib is responsible for the lack of effect has not been determined. It is worth noting that we found that MX-1 tumours had very high PARP activity and 7 days after receiving $150 \mathrm{mg} \mathrm{kg}^{-1}$ dose it was only suppressed by $\sim 75 \%$ compared with $90 \%$ inhibition in the Capan-1 cells. Thus, 7 days after receiving rucaparib, the PARP activity in MX-1 tumours was equivalent to untreated Capan-1 tumours and presumably sufficient to sustain repair of endogenous DNA breaks. However, the continuous schedule of rucaparib was no more effective than the weekly dosing, indicating that it was not because of inappropriate scheduling. To date, the only report of regressions of MX-1 xenografts are following once or twice daily administration of BMN 673, and in this study olaparib at $100 \mathrm{mg} \mathrm{kg}^{-1}$ daily for 28 days was completely ineffective (Shen et al, 2013).

In conclusion the remarkable persistence of PARP inhibition by rucaparib in cell line and xenograft models, shown here for the first time, indicate that where the tumour is sensitive to rucaparib and PARP activity can be maintained below a certain threshold this results in equivalent efficacy of weekly $v s$ daily schedules. These pre-clinical data suggest that clinical trials to evaluate alternative schedules of rucaparib, with appropriate pharmacodynamic monitoring, are warranted.

\section{ACKNOWLEDGEMENTS}

We gratefully acknowledge the support from CR UK (grant number C240/A7409 ) (to JM, SK, CJ and HT) and research funding from Pfizer GRD (awarded to NJC) for this work.

\section{CONFLICT OF INTEREST}

NJC is in receipt of research funding from Pfizer. GL and ZH are former employees of Pfizer. The remaining authors declare no conflict of interest.

\section{REFERENCES}

Bryant HE, Schultz N, Thomas HD, Parker KM, Flower D, Lopez E, Kyle S, Meuth M, Curtin NJ, Helleday T (2005) Specific killing of BRCA2deficient tumours with inhibitors of poly(ADP-ribose) polymerase. Nature 434: 913-917.

Calabrese CR, Almassy R, Barton S, Batey MA, Calvert AH, Canan-Koch S, Durkacz BW, Hostomsky Z, Kumpf RA, Kyle S, Li J, Maegley K, Newell DR, North M, Notarianni E, Stratford IJ, Skalitzky D, Thomas HD, Wang L-Z, Webber SE, Williams KJ, Curtin NJ (2004) Preclinical evaluation of a novel poly(ADP-ribose) polymerase-1 (PARP-1) inhibitor, AG14361, with significant anticancer chemo- and radio-sensitization activity. J Natl Cancer Inst 96: 56-67.

Daniel RA, Rozanska AL, Mulligan EA, Drew Y, Thomas HD, Castelbuono DJ, Hostomsky Z, Plummer ER, Tweddle DA, Clifford SC, Curtin NJ (2010) Central nervous system penetration and enhancement of temozolomide activity in childhood medulloblastoma models by poly(ADP-ribose) polymerase inhibitor AG014699. Br J Cancer 103: $1588-1596$.

De Vos M, Schreiber V, Dantzer F (2012) The diverse roles and clinical relevance of PARPs in DNA damage repair: current state of the art. Biochem Pharmacol 84: 137-146.

Dedes KJ, Wilkerson P, Wetterskog D, Lambros MB, Natrajan R, Tan D, Lord CJ, Kaye SB, Ashworth A, Reis-Filho JS (2011) Preclinical evaluation of the PARP-inhibitor olaparib for the treatment of ovarian clear cell cancer. Geburtsh Frauenheilk 71: doi:10.1055/s-0031-1286501.

Deeken JF, Loscher W (2007) The blood- brain barrier and cancer: transporters, treatment and Trojan horses. Clin Can Res 13: 1663-1674.

Do K, Chen AP (2013) Molecular pathways: targeting PARP in cancer treatment. Clin Cancer Res 19: 977-984.

Drew Y, Mulligan EA, Vong W-T, Thomas HD, Kahn S, Kyle S, Mukhopadhyay A, Los G, Hostomsky Z, Plummer ER, Edmondson RJ, 
Curtin NJ (2011) Therapeutic potential of PARP inhibitor AG014699 in human cancer with mutated or methylated BRCA. J Natl Cancer Inst 103: 334-346.

El-Khamisy SF, Masutani M, Suzuki H, Caldecott KW (2003) A requirement for PARP-1 for the assembly or stability of XRCC1 nuclear foci at sites of oxidative DNA damage. Nucleic Acids Res 31: 5526-5533.

Farmer H, McCabe N, Lord CJ, Tutt AN, Johnson DA, Richardson TB, Santarosa M, Dillon KJ, Hickson I, Knights C, Martin NM, Jackson SP, Smith GC, Ashworth A (2005) Targeting the DNA repair defect in BRCA mutant cells as a therapeutic strategy. Nature 434: 917-921.

Fong PC, Bass DS, Yap TA, Carden CP, Mergui-Roelvink M, Gourley C, De Greve J, Lubinski J, Shanley S, Messiou C, A'Hern R, Tutt A, Ashworth A, Stone J, Carmichael J, Schellens JH, de Bono JS, Kaye SB (2009) Inhibition of poly(ADP-ribose) polymerase in tumours from BRCA mutation carriers. N Engl J Med 361: 123-134.

Javle M, Curtin NJ (2011) The role of PARP in DNA repair and its therapeutic exploitation. Br J Cancer 105: 1114-1122.

Lindahl T (1993) Instability and decay of the primary structure of DNA. Nature 362: 709-715.

Murai J, Huang SY, Das BB, Renaud A, Zhang Y, Doroshow JH, Ji J, Takeda S, Pommier Y (2012) Trapping of PARP1 and PARP2 by clinical PARP inhibitors. Cancer Res 72: 5588-5599.

Nikiforov A, Dölle C, Niere M, Ziegler M (2011) Pathways and subcellular compartmentation of NAD biosynthesis in human cells: from entry of extracellular precursors to mitochondrial NAD generation. J Biol Chem 286: $21767-21778$.

Plummer ER, Middleton MR, Jones C, Olsen A, Hickson I, McHugh P, Margison G, McGown G, Thorncroft M, Watson AJ, Boddy AV, Calvert AH, Harris AL, Newell DR, Curtin NJ (2005) Temozolomide pharmacodynamics in patients with metastatic melanoma: DNA damage and activity of repair enzymes ATase and PARP-1. Clin Cancer Res 11: 3402-3409.

Plummer R, Jones C, Middleton M, Wilson R, Evans J, Olsen A, Curtin N, Boddy A, McHugh P, Newell D, Harris A, Johnson P, Steinfeldt H,
Dewji R, Wang D, Robson L, Calvert H (2008) Phase I study of the poly(ADP-ribose) polymerase inhibitor, AG014699, in combination with temozolomide in patients with advanced solid tumors. Clin Cancer Res 14(23): 7917-7923.

Satoh MS, Lindahl T (1992) Role of poly(ADP-ribose) formation in DNA repair. Nature 356: 356-358.

Shapiro G, Kristeleit R, Middleton M, Burris III H, Molife R, Evans J, Wilson R, LoRusso P, Spicer J, Dieras V, Patel M, Dominy E, Simpson D, Giordano H, Allen AR, Jaw-Tsai SS, Plummer R (2013) Pharmacokinetics of orally administered rucaparib in patients with advanced solid tumours. Mol Cancer Ther 12(11 Suppl): Abstract no. A218.

Shen Y, Rehman FL, Feng Y, Boshuizen J, Bajrami I, Elliott R, Wang B, Lord CJ, Post LE, Ashworth A (2013) BMN 673, a novel and highly potent PARP1/2 inhibitor for the treatment of human cancers with DNA repair deficiency. Clin Cancer Res 19(18): 5003-5015.

Sofue M, Yoshimura Y, Nishida M, Kawada J (1992) Possible multifunction of glucose transporter. Transport of nicotinamide by reconstituted liposomes. Biochem J 288(Pt 2): 669-674.

Thomas HD, Calabrese CR, Batey MA, Canan S, Hostomsky Z, Kyle S, Maegley KA, Newell DR, Skalitzky D, Wang L-Z, Webber SE, Curtin NJ (2007) Preclinical selection of a novel poly(ADP-ribose) polymerase inhibitor for clinical trial. Mol Cancer Ther 6: 945-956.

Wahlberg E, Karlberg T, Kouznetsova E, Markova N, Macchiarulo A, Thorsell AG, Pol E, Frostell Å, Ekblad T, Öncü D, Kull B, Robertson GM, Pellicciari R, Schüler H, Weigelt J (2012) Family-wide chemical profiling and structural analysis of PARP and tankyrase inhibitors. Nat Biotechnol 30: $283-288$.

This work is published under the standard license to publish agreement. After 12 months the work will become freely available and the license terms will switch to a Creative Commons AttributionNonCommercial-Share Alike 3.0 Unported License.

Supplementary Information accompanies this paper on British Journal of Cancer website (http://www.nature.com/bjc) 